\title{
PROJETO DE UMA FONTE DE TENSÃO MICROCONTROLADA DE BAIXO CUSTO COM O INTUITO DE AUXILIAR NO PROCESSO DE ENSINO DE CIRCUITOS ELETRÔNICOS
}

\author{
Douglas F. Copetti - douglas.copetti@sou.unijui.edu.br \\ Universidade Regional do Noroeste do Estado do Rio Grande do Sul (UNIJUÍ), \\ Departamento de Ciências Exatas e Engenharias \\ R. Lulu Ingelfritz, 480 - São Geraldo \\ 98700000 - Ijuí - Rio Grande do Sul
}

Resumo: O presente trabalho se refere ao desenvolvimento do projeto de uma fonte ajustável de tensão com um range de até $30 \mathrm{~V}$ (volts) e $5 \mathrm{~A}$ (amperes). A qual opere com base em um circuito de amplificação unitária, sendo esse sistema microcontrolado de modo a possibilitar tanto um ajuste de parâmetros manual quanto digitalizado, por meio de uma interface gráfica. Tal interface permite ajustar a tensão de operação, a corrente máxima da fonte e receber as leituras atuais desses valores. Além disso, esse projeto observa diferentes modos de proteção, nesse sentido desabilita-se a saída em caso de uma corrente superior a máxima estabelecida ou de uma temperatura interna elevada que possa levar o sistema a sofrer danos. Contudo, busca-se manter um baixo valor do projeto para que seja acessivel, isso levando em conta a necessidade desse instrumento no ensino relacionado a engenharia elétrica ou eletrônica. De modo a oferecer uma solução para a carência desse instrumento no contexto do ensino de circuitos eletrônicos.

Palavras-chave: Educação online. Fonte de tensão ajustável. Interface gráfica.

\section{INTRODUÇÃO}

No âmbito seja da engenharia elétrica ou eletrônica, algo basilar para gerar o engajamento do aluno é o desenvolvimento de uma fonte de tensão ajustável de baixo custo para uso individual ou em pequenos grupos, haja vista que possibilita a execução de diversos experimentos, aproximando o aluno de conceitos pertinentes de forma indubitavelmente singular. De modo que a curva de aprendizagem do discente torna-se mais rápida, permitindo o desenvolvimento de projetos sem a necessidade de deslocamentos até os laboratórios da instituição de ensino, podendo assim ter maior foco além de resultados mais robustos no desenvolvimento do aluno. Contudo, é no ensino a distância ou da modalidade online que esse projeto ganha ainda mais peso. Visto que proporciona ao aluno essa imersão prática característica da montagem de circuitos.

Nesse sentido, é importante considerar que o conhecimento pode ser classificado em duas categorias, conhecimento declarativo e conhecimento procedural (STERNBERG, 2000). O primeiro pode ser descrito sendo o uso da analogia para explicar algo a outrem, estando esse muito presente nas abstrações para o ensino dos alunos (OLIVEIRA; MOZZER, 2017). Já o segundo é relacionado a um algoritmo mental, ou seja, os passos para realizar-se algo (FERREIRA; et al., 2014). É essencial que o discente compreenda o conteúdo, mas também é 
necessário que se saia da abstração teórica para observar os fenômenos na prática, compreender os cuidados necessários no trato de circuitos eletrônicos reais e desenvolver seu processo de montagem. Todavia, apesar das instituições de ensino dedicarem-se a passar a experiência de ambos, é comum que falte tempo no período normal das aulas para o aluno desenvolver-se na prática da montagem de circuitos, necessitando muitas vezes deslocar-se em um horário específico para tal. Por isso, a justificativa desse trabalho é um esforço para produzir o básico, nesse sentido, para que os discentes possam desenvolver-se em casa, sem a necessidade de deslocamento, de modo a incentivar a busca por conhecimento.

Sendo assim, desenvolveu-se o projeto de uma fonte de tensão ajustável de baixo preço com range de até $30 \mathrm{~V}$ e $5 \mathrm{~A}$, haja visto que esses níveis de alimentação suprem a necessidade de uma grande parcela das aplicações de circuitos eletrônicos, sendo inclusive superior a várias fontes comerciais, como por exemplo a fonte regulável do modelo PS15022DD que opera até $15 \mathrm{~V}$ e $3 \mathrm{~A}$. Além disso, por se destinar a discentes, tomou-se o cuidado de adicionar modos de proteção ao equipamento e ainda uma interface gráfica que facilita o processo de configuração da fonte.

O projeto foi desenvolvido por meio da utilização de softwares e projeto de circuitos eletrônicos e elétricos. Nesse sentido, a simulação do hardware foi realizada através do programa de simulação de circuitos Proteus, baseado em SPICE (Simulation Program with Integrated Circuit Emphasis). Enquanto a criação e debug do software de controle do microcontrolador se deu através do ambiente PIC C Compiler, no qual se utiliza a linguagem de programação C. Já a criação da malha de controle foi possível mediante o software matemático Matlab. Além desses, para o sistema de supervisão utilizou-se da linguagem Python por meio do programa Visual Studio Code.

\section{PROJETO DO HARDWARE}

Mediante o objetivo de um baixo custo, projetou-se um hardware com componentes de pequeno valor de mercado. Dentre eles estão um microcontrolador PIC16F877A, ou seja, de uma família mais simples, mas que atende bem para esse projeto. Assim como um transformador para abaixamento da tensão da rede para $30 \mathrm{~V}$. Além de um amplificador operacional LM358, o qual não necessita de uma fonte simétrica para alimentação. Também se conta com um sensor de temperatura analógico LM35, um display de 16 colunas por 2 linhas, um conversor de nível MAX232, um regulador de tensão LM7805 dentre outros componentes básicos de eletrônica como resistores, capacitores, transistores e LEDs (Light Emittig Diode).

\subsection{Abaixamento, Retificação e Filtragem}

A tensão é abaixada através do transformador até o nível de projeto. Conforme Torres (2018), posteriormente há a retificação por meio da ponte de diodos, ou seja, a tensão alternada é transformada em uma tensão chamada pulsante. Por isso, aplica-se uma filtragem com capacitor que transforma a onda pulsante em tensão contínua. Contudo, ainda há uma pequena oscilação chamada de ripple. Sendo o circuito final da retificação desenvolvido apresentado na Figura 1. Além disso, adicionando um regulador de tensão LM7805 é possível rebaixar ainda mais a tensão, de modo a alimentar o microcontrolador e demais circuitos que operam a níveis lógicos TTL (Transistor-Transistor Logic). 


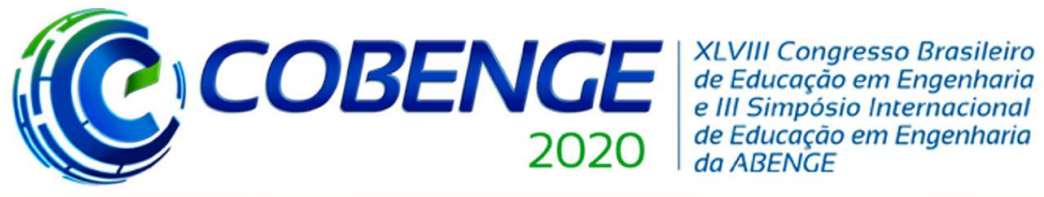

"Os desafios para formar hoje o engenheiro do amanhã"

Figura 1 - Circuito de retificação completo.

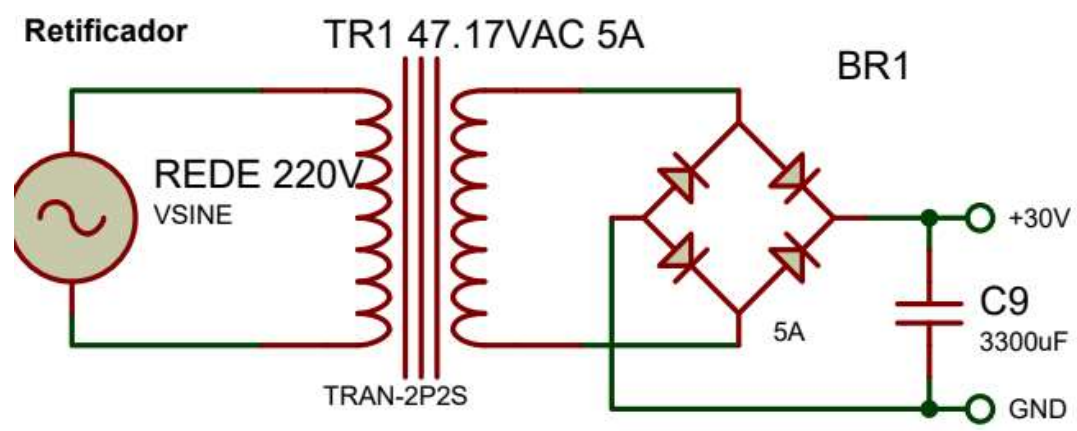

Fonte: Autores (2020)

\subsection{Circuito seguidor de tensão: o circuito básico da fonte}

Um circuito seguidor de tensão apresenta amplificação unitária, ou seja, o sinal de saída é idêntico ao sinal de entrada (TORRES 2019). Nesse contexto, é possível afirmar que o amplificador ajusta a tensão de sua porta de saída de forma a igualar a tensão entre suas entradas e esse é o funcionamento básico de um seguidor de tensão. Desse modo, aplicando uma tensão de referência na porta não inversora obtém-se um sinal idêntico na porta inversora. Com o diferencial de adicionar-se transistores para possibilitar um ganho de corrente ao circuito. Nesse caso, na configuração Darlington uma vez que assim se é capaz de trabalhar com um alto ganho de corrente, sendo esse o produto dos ganhos individuais dos transistores. Na Figura 2 é apresentado o circuito base da fonte, no qual nota-se o amplificador operacional em topologia de seguidor de tensão acoplado com os transistores em par Darlington. Nesse contexto, escolheu-se trabalhar com um BC547 como transistor de primeiro estágio do par, pois ele suporta o nível de tensão desejado, no caso $30 \mathrm{~V}$ de alimentação. Além de ser capaz de suportar níveis de corrente para acionar o segundo transistor, como pode ser confirmado na sua ficha de especificações. Já o segundo transistor foi selecionado por além de poder atuar com a alimentação escolhida, ter segundo seu fabricante uma corrente de coletor de até $15 \mathrm{~A}$ desde que sua temperatura seja inferior a $200^{\circ} \mathrm{C}$. Trata-se, portanto, do transistor $2 \mathrm{~N} 3055$.

Figura 2 - Circuitos básico da fonte.

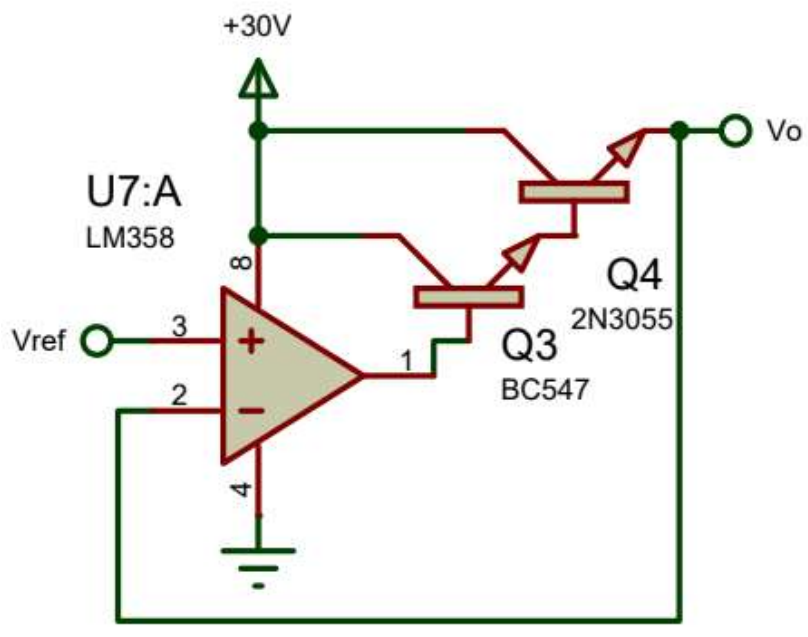

Fonte: Autores (2020) 


\subsection{Sistema de resfriamento}

Conforme o datasheet do fabricante, o circuito integrado 2N3055 quando utilizado em sua capacidade nominal, dissipa grande capacidade de calor. Para evitar a perda do componente, é necessário um sistema de resfriamento, de modo a mantê-lo em operação dentro dos parâmetros desejados. Devido a isso, adicionou-se um sensor de temperatura LM35, que conforme TEXAS INSTRUMENTS (1999) é um dispositivo de precisão que pode ser alimentado entre $4 \mathrm{~V}$ e $20 \mathrm{~V}$ para assim gerar uma indicação da variação térmica no case do 2 N3055. Este dado é processado pelo microcontrolador de modo que a temperatura sendo superior a $45^{\circ} \mathrm{C}$ (graus Celsius), o sistema de refrigeração é ativado. Se o sistema não conseguir estabilizar a temperatura do componente abaixo de $145^{\circ} \mathrm{C}$, então automaticamente a saída é desabilitada, entrando em modo de proteção até que a temperatura não ofereça mais nenhum risco a fonte. Nesse sentido, o sistema acionado pelo microcontrolador para operar o resfriamento do $2 \mathrm{~N} 3055$ é composto por um transistor que sofre polarização com base em um resistor de $1.000 \Omega$ (ohms), de forma que quando solicitado o mesmo seja capaz de realizar o chaveamento de um relé, de modo a alimentar o cooler responsável por resfriar o componente com base em ventilação forçada, o sistema descrito pode ser visualizado na Figura 3.

Figura 3 - Sistema de resfriamento.

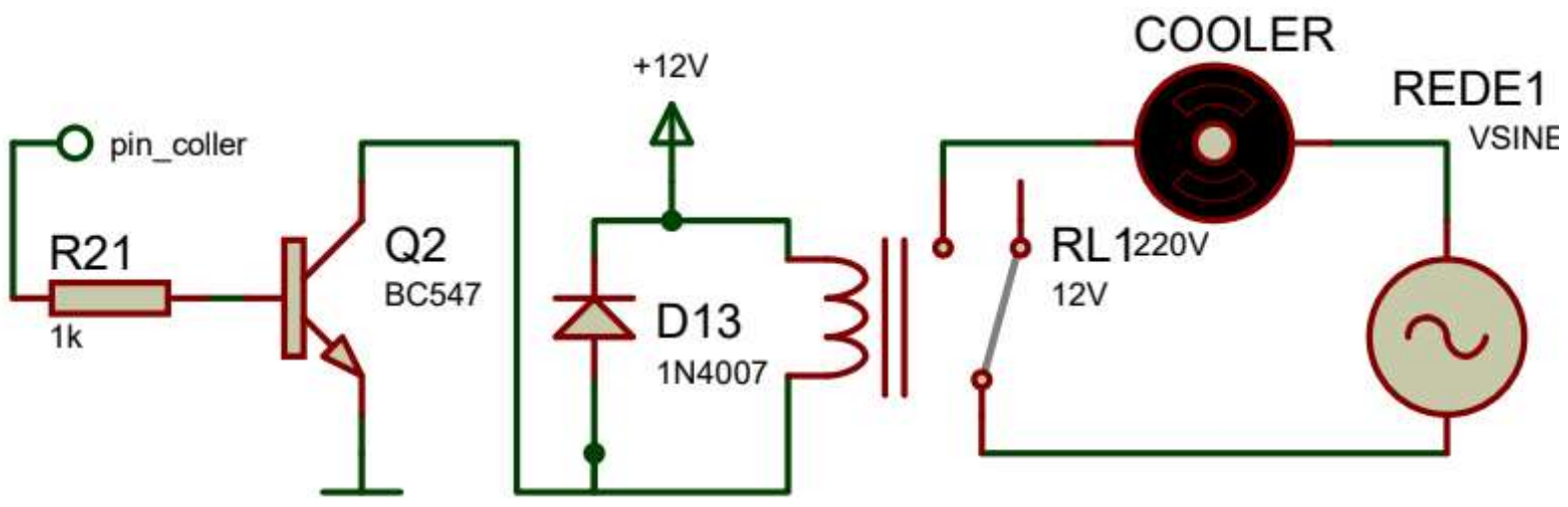

Fonte: Autores (2020)

\subsection{Filtro passa-baixas para a modulação de largura de pulso}

Conforme visto anteriormente, necessita-se aplicar uma tensão de referência na porta do circuito base da fonte. Essa tensão é escolhida pelo usuário por meio de um potenciômetro, então é gerada a partir de um microcontrolador. Nesse contexto, existem dois problemas principais, o primeiro é que o microcontrolador trabalha de forma digital, tendo em suas saídas um estado alto ou baixo, mas não níveis intermediários. Já o segundo problema é relacionado ao valor do nível alto correspondente a $5 \mathrm{~V}$, enquanto deseja-se trabalhar até $30 \mathrm{~V}$. Por isso, para resolver o primeiro problema utiliza-se o conceito de PWM (Pulse Width Modulation), de forma que é simulada uma onda analógica através do controle da largura de pulso de uma onda digital advinda da saída do microcontrolador, com uma frequência de $2000 \mathrm{~Hz}$ (hertz). Posteriormente, aplicando esse sinal a um filtro passa-baixas de $5 \mathrm{~Hz}$ para resultar na saída apenas a componente em tensão contínua do sinal. Dessa forma resolve-se o primeiro problema e para o segundo adiciona-se a esse filtro um ganho de 6 vezes, possibilitando que o sistema opere até a tensão desejada.

Conforme Boylestad e Nashelsky (2013), os amplificadores operacionais são frequentemente utilizados na construção de filtros ativos, para produzir amplificação de tensão e servir como buffer ou isolação do sinal. No caso do filtro passa-baixas, apresenta-se resposta constante até uma frequência de corte que impede que qualquer sinal além dessa frequência, passe para a saída. Com base nisso, elaborou-se o circuito demonstrado na Figura 
(C) COBENCE

"Os desafios para formar hoje o engenheiro do amanhã"
O1 a 03 de dezembro Evento On-line

4, na qual pode-se notar o uso de resistores e de um capacitor associados a um amplificador operacional, ou seja, trata-se de um filtro ativo de primeira ordem com ganho de 6 vezes, conforme projetado para atender as especificações citadas no parágrafo anterior.

Figura 4 - Filtro ativo passa-baixas.

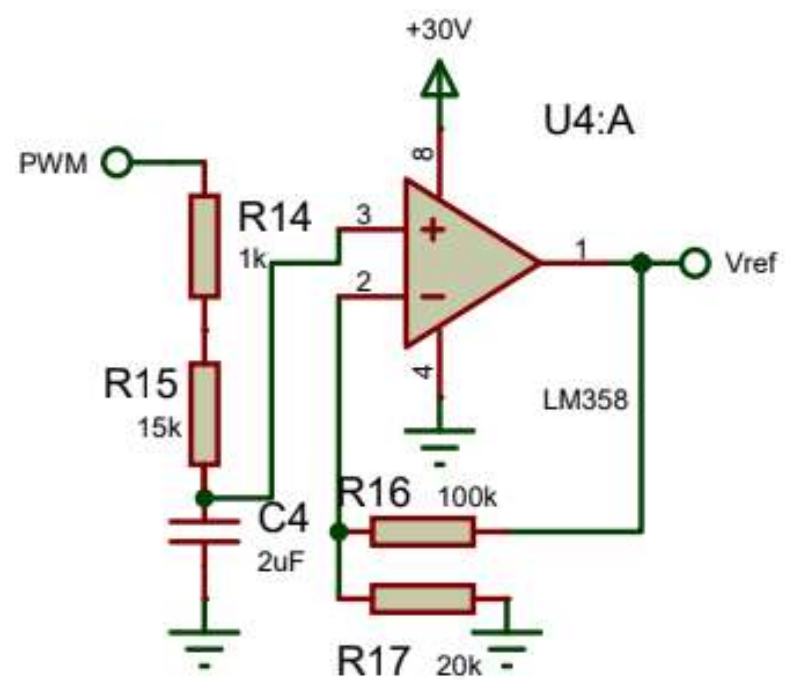

Fonte: Autores (2020)

\subsection{Leitura de dados}

Há parâmetros que necessitam de leitura neste projeto, são eles a tensão de saída do sistema e a corrente drenada da fonte. Nesse sentido, o microcontrolador consegue efetuar a leitura de no máximo $5 \mathrm{~V}$ nos pinos analógicos. Por isso, e considerando que o projeto da fonte é para $30 \mathrm{~V}$, se faz necessário um circuito para abaixar essa tensão até o limite aceitável. Desse modo, um divisor resistivo foi utilizado em conjunto com um buffer, haja vista que para o processo de leitura analógica é necessário o descarregar de um capacitor intrínseco a esse processo, segundo o datasheet do componente. Isso não seria possível diretamente no divisor resistivo devido a seu alto valor ôhmico, na faixa de mega ohms. Por esse motivo, adicionou-se o buffer, de modo a realizar o devido casamento de impedância; possibilitando, assim, uma correta leitura de tensão. $\mathrm{O}$ arranjo descrito é ilustrado na Figura 5.

Figura 5 - Circuito para leitura de tensão

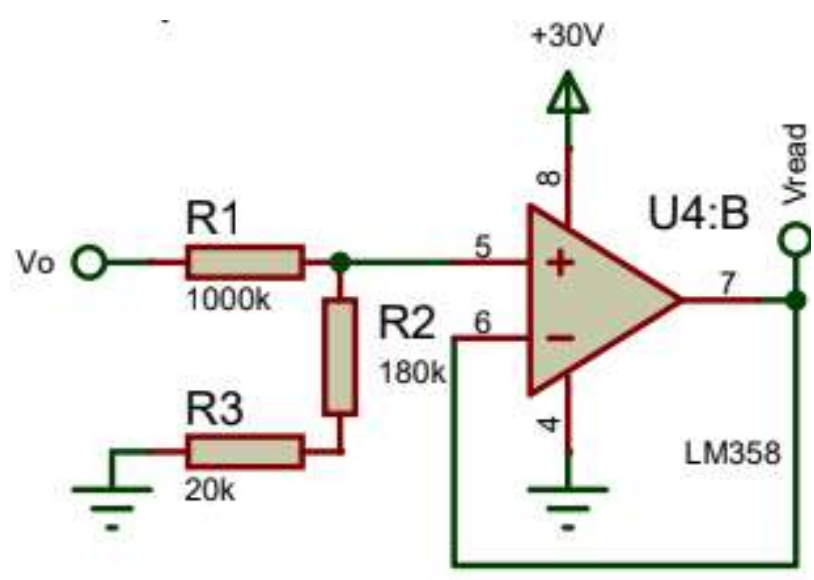

Fonte: Autores (2020) 
Já a aferição de corrente não pode ser realizada diretamente pelo microcontrolador, que só é capaz de ler tensão, tornando preciso o uso de algum elemento auxiliar. Nesse ínterim, a técnica para leitura é através de um resistor shunt colocado em série com a carga, dessa forma a corrente drenada flui por esse resistor. Logo, ao ler-se a tensão sobre o resistor shunt conhece-se também o valor da corrente, mediante a aplicação da lei de Ohm clássica, a qual relaciona tensão como o produto entre resistência e corrente elétrica.

\subsection{Interface física para ajuste da tensão e corrente máxima}

Pode-se configurar os parâmetros da fonte de dois modos. Um por meio de uma interface gráfica e outro através de botões e potenciômetros, o primeiro será abordado no decorrer da próxima seção. Já o segundo modo, permite a escolha da tensão por um potenciômetro e da corrente máxima por outro, além de habilitar/desabilitar a saída, ou ainda navegar nas informações do display por meio de botões. Nesse contexto, o display apresenta os dados pertinentes da fonte, como a leitura da tensão, da corrente e alertas de quando a fonte entra em modo de proteção.

\section{DESENVOLVIMENTO DE SOFTWARE}

Elaborou-se um código de controle para o microcontrolador em linguagem C, por meio da IDE (Integrated Development Environment) do PIC C Compiler. Todavia, para que o controle fosse efetivo era necessário encontrar os valores de ganhos associados a planta do sistema, tal processo será melhor descrito na sequência. Além disso, desenvolveu-se uma interface gráfica responsável por supervisionar o sistema.

\subsection{Elaboração do código}

Conforme supracitado, fez-se uso da linguagem C para programação do microcontrolador PIC16F877A. Assim, pode-se configurar o clock do sistema para $20.000 .000 \mathrm{~Hz}$, por proporcionar um processamento mais ágil. Nesse sentido, ajustou-se o timer0 para gerar interrupções por overflow a cada 0,010 s (segundos) de modo a possibilitar bases de tempo múltiplas da original como $0,020 \mathrm{~s}, 0,050 \mathrm{~s}$ e $1 \mathrm{~s}$. Ainda no contexto de temporização, o timer 2 foi configurado para gerar o PWM de frequência equivalente a $2.000 \mathrm{~Hz}$ relacionado a tensão de referência mencionada na seção 2.3. Além disso, selecionou-se 10 bits para o conversor A/D (analógico-digital), afim de obter a resolução máxima disponível para leitura. Ainda se habilitou uma interrupção para comunicação RS232, utilizada na troca de dados com a interface gráfica. Pois, em muitas aplicações microcontroladas é útil realizar uma comunicação entre o microcontrolador e dispositivos externos (PEREIRA, 2003).

Outrossim, o código conta com definições de modo a promover organização e diminuir a memória que seria gasta utilizando-se variáveis para tal. Nessas definições é contido valores de configuração tanto dos timers quanto de mais alguns parâmetros da fonte como temperatura máxima, corrente crítica e dos ganhos do controle PID (proporcional integral derivativo). Optou-se por esse tipo de controle haja vista sua alta precisão, característica atrativa ao projeto. De modo que ao incrementar a rotina de cálculo do controle com os valores de leitura da corrente e tensão, os quais são atualizados por funções chamadas dentro das bases de tempo, chega-se ao valor ideal para o sinal de referência necessário ao sistema.

Contudo, para liberar essa nova saída é executada uma função de verificação, pela qual se é atualizado e monitorado diversas flags, que indicam situações em que a saída pode ou não ser liberada. Como por exemplo, se a temperatura atingida no case do 2 N3055 pode provocar a queima do mesmo, ou ainda se a corrente passou de seu valor crítico. Em ambas situações é 
sinalizado isso por meio de LEDs de indicação, do display e da interface gráfica. Além de entrar em modo de proteção em que a saída da fonte é desabilitada até que se retorne as condições de operação ideais. Todavia, se a situação está dentro da normalidade e as flags indicam que a saída pode ser liberada, essa de fato é liberada. Sendo na sequência, executado a função de verificação da necessidade do acionamento do cooler. A qual julga com base na comparação do valor da temperatura lida com valores configurados se é necessário ou não ligar a ventilação. Depois disso, o processo volta a acontecer, todavia, seguindo as bases de tempo, haja vista que devido ao bom manuseio dos timers, bem como do uso das funções não foi necessário utilizar-se de linhas de código dentro de um loop infinito, como é comum de ser encontrado no contexto de programação de microcontroladores.

\subsection{Determinação dos ganhos do controle}

Para calcular os ganhos de um compensador é necessário encontrar a função de transferência. A qual represente a relação das grandezas de saída e entrada de um sistema (VASCONCELOS, 2001), sendo essa composta por uma parcela de resposta natural do circuito somada de uma parcela de resposta particular. Existem diferente métodos para encontrar essa função. Nesse projeto realizou-se uma simulação computadorizada e exportouse os dados para o Matlab. Dessa forma, chegou-se à função descrita na Equação 1.

$$
G(S)=\frac{120000}{640 S+20000}
$$

$\mathrm{Na}$ sequência, foi possível utilizar a ferramenta Simulink do Matlab, para simular o sistema em malha fechada, e por meio da opção Tune do bloco PID, foi possível realizar a sintonia dos ganhos, isso com base nos critérios estabelecidos no projeto. Dessa forma, os valores encontrados foram um ganho proporcional de 2,6266, um ganho integral de 363,2268 e um ganho derivativo de 0,0013 . Com esses valores pode-se simular o circuito referente ao controle de tensão.

\subsection{Interface gráfica}

O sistema supervisório foi desenvolvido utilizando a linguagem de programação Python na versão 3.8.3, esta linguagem foi escolhida por ser gratuita e multiplataforma, funcionando tanto em Linux, Mac OS e Windows. Na Figura 6, é apresentado a janela da interface gráfica, na qual a opção "Status da Fonte" permite enviar um comando para ligar ou desligar a fonte, enquanto as opções "Seleção da Tensão" e "Corrente Máxima" dizem respeito ao ajuste de tensão de operação e máxima corrente a ser drenada do sistema. 
(C) COBENGE 2020

"Os desafios para formar hoje o engenheiro do amanhã"

Figura 6 - Janela da interface gráfica

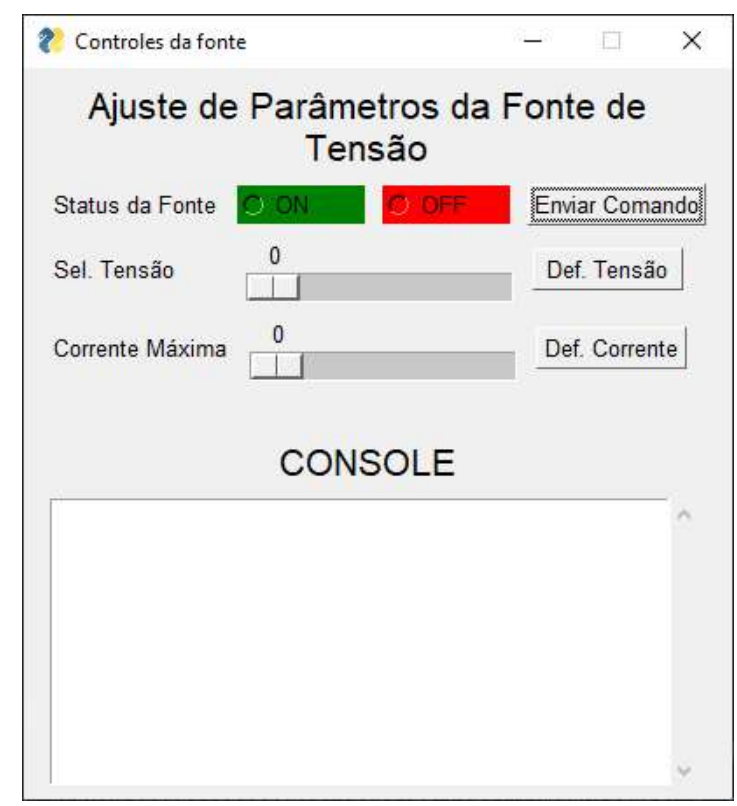

Fonte: Autores (2020)

Já a área "CONSOLE", mostra em tempo real, algumas informações referentes à fonte, tais dados são recebidos via UART (Universal Asynchronous Receiver/Transmitter). Na Figura 7 é demonstrado a exibição.

Figura 7 - Console com informações

\section{CONSOLE}

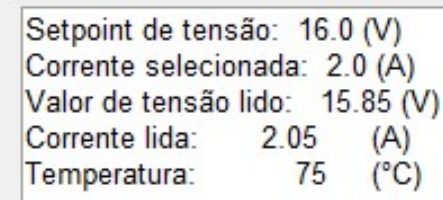

Fonte: Autores (2020)

Nesse contexto, caso a temperatura monitorada no case do 2N3055 esteja alta, é realizado um alerta no console. E se a temperatura do componente for superior a $130^{\circ} \mathrm{C}$, uma mensagem é exibida sobre a temperatura estar muito alta e a possibilidade de o sistema ser desligado para evitar perda de componentes, como é apresentado na Figura 8. Nesse sentido, também são executados comandos de proteção no caso de sobrecorrente. 
"Os desafios para formar hoje o engenheiro do amanhã"

Figura 8 - Alerta de estado crítico do sistema

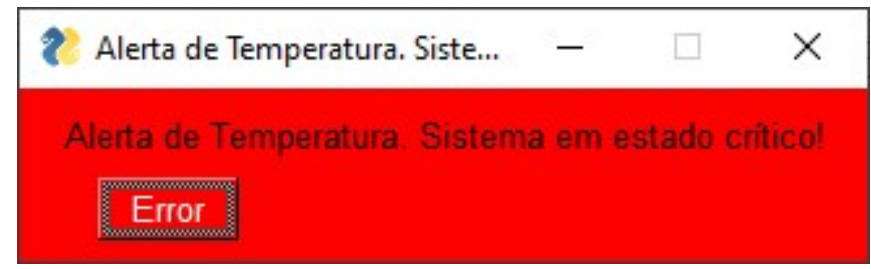

Fonte: Autores (2020)

\section{CONSIDERAÇÕES FINAIS}

Todos os circuitos desenvolvidos atenderam às expectativas e aos parâmetros inicialmente estabelecido no início do projeto, com exceção da tensão máxima que se objetivou $30 \mathrm{~V}$, mas na prática a obtida foi de $28 \mathrm{~V}$. Todavia, essa variação é pequena, de forma que $28 \mathrm{~V}$ continua abrangendo a maior parcela dos circuitos eletrônicos. Contudo, isso cabe como sugestão de melhoria futura. Nesse contexto, todos os demais parâmetros e objetivos foram atingidos, e os circuitos mostram ótimas respostas perante a simulação, não só de forma individual, mas em conjunto.

Para melhor definir, é citado a funcionalidade da configuração de tensão de operação e corrente máxima desejada. As interfaces relacionadas, o circuito base da fonte associado ao passa-baixas do PWM. Além, dos circuitos para leitura de tensão, corrente e temperatura, sendo esse último associado ao sistema de refrigeração. Em soma também, todas as rotinas propostas na programação e os diferentes modos de operação ativados por flags especiais.

Nesse contexto, os componentes usados visaram um baixo custo. Sendo que para elaboração desse projeto os mesmos se encontravam presentes na instituição de ensino do autor, todavia consultando seus valores em lojas, conclui-se que em julho de 2020, com menos de R\$ 150 pode-se elaborar a fonte proposta. Assim, mantendo a proposta de um baixo custo. Conclui-se que o projeto básico foi um sucesso, no sentido em que os circuitos projetados e simulados são funcionais e os objetivos foram atendidos. Sendo as respostas apresentadas pelos circuitos, equivalentes ao esperado no projeto dos mesmos.

\section{Agradecimentos}

O autor agradece ao Grupo de Automação Industrial e Controle (GAIC) e a instituição de ensino Universidade Regional do Noroeste do Estado do Rio Grande do Sul (UNIJUÍ) tanto por disponibilização de infraestrutura quanto de equipamentos necessários para o desenvolvimento do projeto.

\section{REFERÊNCIAS}

BOYLESTAD, Robert; NASHELSKY, Louis. Dispositivos Eletrônicos e Teoria de Circuitos. 11 edição, São Paulo: Perason Education do Brasil, 2013.

FAIRCHILD SEMICONDUCTOR, BC546/547/548/549/550. Datasheet. 2002. 
"Os desafios para formar hoje o engenheiro do amanhã"

FERREIRA, Golberi S. et al. Enriched scenarios for teaching and learning electronics. In: 2014 XI Tecnologias Aplicadas a la Ensenanza de la Electronica (Technologies Applied to Electronics Teaching)(TAEE). IEEE. p. 1-6. 2014.

MICROCHIP TECHNOLOGY, PIC16F87XA. Datasheet. 2013.

OLIVEIRA, T.; MOZZER, N. Análise dos conhecimentos declarativo e procedimental de futuros professores de química sobre analogias. Ens. Pesqui. Educ. Ciênci. (Belo Horizonte), Belo Horizonte, v. 19, e2602, 2017.

PEREIRA, Fábio. Microcontrolador PIC: programação em C. $1^{\text {o }}$ edição, São Paulo: Editora Érica, 2003.

SEMICONDUCTOR COMPONENTS INDUSTRIES, 2N3055/D. Datasheet. 2005.

STERNBERG, Robert. Psicologia cognitiva. $1^{\circ}$ edição, Porto Alegre: Artmed Editora S.A, 2000 .

TEXAS INSTRUMENTS. LM35 Precision Centigrade Temperature Sensors. Datasheet. 1999.

TORRES, Gabriel. Eletrônica para Autodidatas, Estudantes e Técnicos. $2^{\circ}$ edição, Rio de Janeiro: SF Editorial, 2018.

VASCONCELOS, José. Determinação da Função de Transferência de Transformador de Potencial Capacitivo. 2001. Dissertação (Mestrado) - Universidade Federal da Paraíba, Campina Grande, 2001.

\title{
PROJECT OF A LOW COST MICROCONTROLLED VOLTAGE SOURCE WITH THE PURPOSE OF SUPPORT IN THE ELECTRONIC CIRCUIT TEACHING PROCESS
}

\begin{abstract}
This present scientific work refers to the development of the project of an adjustable voltage source with a range of up to 30 Volts $(V)$ and 5 Amps (A). Which operates based on a buffer circuit, this system being microcontrolled in order to allow both manual and digital parameter adjustment, through a graphical interface. Such interface allows to adjust the operating voltage, the maximum current of the source and to receive the actual reading of these values. In addition, this project observes different modes of protection, in this sense, the output is disabled in the event of a current higher than the established maximum or a high internal temperature than can cause the system to suffer damage. However, it seeks to maintain a low value of the project so that it is accessible, taking into account the need for this instrument in teaching related to electrical or electronic engineering. In order to offer a solution to the lack of this instrument in the context of teaching electronic circuits.
\end{abstract}

Keywords: Online education. Adjustable voltage source. Graphic interface. 